\title{
Disciplina de mercado no setor bancário angolano: uma análise da monitorização realizada pelos depositantes
}

\author{
CARLOS MOTA ${ }^{1}$
}

${ }^{1}$ Instituto Politécnico do Porto (P.Porto) / Instituto Superior de Contabilidade e Administração do Porto, Centro de Estudos Organizacionais e Sociais do Politécnico do Porto (ISCAP/CEOS.PP), Portugal

\begin{abstract}
Resumo
Este estudo analisa a disciplina do depositante bancário em Angola, um mercado emergente. Investiga se os depositantes são capazes de monitorizar os riscos bancários, reconhecendo e penalizando os bancos mais arriscados por meio das alterações nos depósitos e juros pagos. Utiliza os dados anuais de um painel de instituições bancárias angolanas, no período entre 2008 e 2017, para analisar o impacto e valor explicativo dos fatores de risco no comportamento dos depositantes. Os resultados sugerem não haver evidência consistente de disciplina de mercado. Os depositantes angolanos se mostram pouco receptivos ao risco bancário, após controle de outros fatores, e a capacidade explicativa global dos modelos de regressão é reduzida. No entanto, nem todos os fatores de risco evidenciam a mesma ausência de preponderância. Evidenciase, ainda, que a disciplina não difere entre os vários grupos de bancos em função da proveniência e propriedade do capital e que a monitorização dos comportamentos de risco efetuada pelos depositantes não foi significativamente alterada pela crise econômica e financeira angolana.
\end{abstract}

Palavras-chave: Disciplina de mercado. Riscos bancários. Depósitos. Angola. 


\title{
Market discipline in the Angolan bank sector: an analysis of the monitoring carried out by depositors
}

\begin{abstract}
This study analyzes the discipline of bank depositors in Angola, an emerging market. It seeks to investigate whether depositors are able to recognize bank risks and penalize the riskiest banks through changes in deposits and interest payments. It uses the annual data of a panel of Angolan banking institutions, between 2008 and 2017, to analyze the impact and explanatory value of risk factors on depositors' behavior. The results suggest that there is no consistent evidence of market discipline. Angolan depositors are not very receptive to banking risk, after controlling for other factors, and the overall explanatory capacity of the regression models is reduced. However, not all risk factors show the same lack of preponderance. The study also shows that the discipline does not differ for different groups of banks because of the provenance and ownership of their capital, and that the monitoring by depositors of banks' risk behaviors has not been significantly altered by the Angolan economic and financial crisis.
\end{abstract}

KeYwords: Depositor discipline. Bank risks. Deposits. Angola.

\section{Disciplina de mercado en el sector bancario angoleño: un análisis de la monitorización realizada por los depositantes}

\section{Resumen}

Este estudio analiza la disciplina del depositante bancario en Angola, un mercado emergente. Investiga si los depositantes son capaces de monitorear los riesgos bancarios, reconociendo y penalizando a los bancos más arriesgados a través de alteraciones en los depósitos e intereses pagados. Utiliza los datos anuales de un panel de instituciones bancarias angoleñas en el período comprendido entre 2008 y 2017 para analizar el impacto y el valor explicativo de los factores de riesgo en el comportamiento de los depositantes. Los resultados sugieren que no existe evidencia consistente de disciplina de mercado. Los depositantes angoleños se muestran poco receptivos al riesgo bancario, después del control de otros factores, y la capacidad explicativa global de los modelos de regresión es reducida. Sin embargo, no todos los factores de riesgo evidencian la misma ausencia de preponderancia. El estudio evidencia que la disciplina no difiere entre los diversos grupos de bancos en función de la procedencia y propiedad del capital y que la monitorización de los comportamientos de riesgo efectuada por los depositantes no fue significativamente alterada por la crisis económica y financiera angoleña.

Palabras clave: Disciplina de mercado. Riesgos bancarios. Depósitos. Angola. 


\section{Introdução}

Este estudo se centra no setor bancário de um país emergente - Angola - e analisa a disciplina de mercado exercida pelos depositantes. O significado de um mercado bancário emergente decorre do risco específico associado a ele. Embora cada mercado seja diferente, há certo número de características que, em graus variados, podem ser encontradas em mercados bancários pouco maduros: menor estabilidade; instituições mais fracas; e governança corporativa deficiente (OLSSON, 2002).

A potencial instabilidade do sistema bancário impulsiona a necessidade de regulamentação financeira. Nesse contexto, o terceiro pilar do Basileia II destaca o papel da disciplina de mercado - mecanismo por meio do qual os agentes do setor privado controlam a assunção de riscos pelos bancos - para aliviar a pressão sobre os meios tradicionais de monitorização, como a supervisão pública. Em mercados menos desenvolvidos, a disciplina do depositante é a forma da disciplina de mercado mais comum para corrigir o comportamento dos bancos.

A evolução do setor bancário pode ser condicionada por características exclusivas de um país e da sua fase de desenvolvimento. Este estudo de caso busca contribuir com a literatura empírica fornecendo evidências sobre o papel dos depositantes no mercado bancário angolano e sua capacidade de participar na minimização dos comportamentos de risco. Vale destacar que Angola ainda não conta com um regime de garantia de depósitos explícito em vigor, o que possibilita analisar a disciplina dos depositantes sob outra perspectiva. Na última década o setor se desenvolveu e flexibilizou com uma abordagem mais ajustada ao mercado; as instituições que o integram controlam a maioria dos fluxos financeiros e detêm a maior parte dos ativos financeiros da economia, portanto, garantir sua solidez é um objetivo primordial do regulador do mercado. Como se verá em detalhe, os resultados deste estudo sugerem uma disciplina de mercado reduzida e subsequentes incentivos ao risco moral. A monitorização efetuada pelos depositantes se mostra insuficiente para garantir decisões de risco adequadas por parte dos bancos.

Após esta breve introdução, o artigo se organiza assim: a primeira seção apresenta uma revisão da literatura sobre a disciplina do depositante; a segunda seção caracteriza a evolução do mercado bancário angolano; a terceira e a quarta seções descrevem a metodologia e os dados, respectivamente; já a quinta seção apresenta e discute os resultados, abrindo caminho para nossa conclusão.

\section{Disciplina de mercado e disciplina do depositante}

Como indica Greenspan (2001), a disciplina de mercado age essencialmente como supervisão privada da contraparte no setor bancário. Pode ser definida como uma situação em que os agentes do setor privado enfrentam aumentos potenciais de perdas à medida que os bancos assumem riscos e, como consequência, tomam decisões com base nesses potenciais custos (BERGER, 1991). Assim, a disciplina de mercado pode ser expressa como um instrumento para salvaguardar a estabilidade do sistema financeiro, tornando mais dispendiosa a assunção de riscos excessivos (NIER e BAUMANN, 2006). 
Hamalainen, Hall e Howcroft (2003) destacam os vários benefícios sociais para o sistema bancário da disciplina de mercado. Primeiro, penalizando os bancos de elevado risco e reduzindo os incentivos ao risco moral. Segundo, pressionando-os a se tornarem mais eficientes ou a abandonarem o setor. Terceiro, como argumentam Ghosh e Das (2003), os mercados sinalizam a situação financeira das instituições, o que, combinado às informações obtidas pelos supervisores, possibilita reforçar a eficácia do processo de supervisão.

A disciplina pode ser sinalizada por três grupos principais de participantes do mercado bancário: depositantes; detentores de dívida; e detentores de capital. Llewellyn (2002) desenvolve o conceito de partes interessadas na monitorização, que surgem associadas a quem tem algo em jogo no sucesso ou insucesso de uma instituição. Por exemplo, os depositantes podem retirar seus depósitos e deslocá-los para um banco mais seguro ou exigir maior rendimento (taxa de juros), aumentando o custo dos fundos para as instituições com maior risco. Por outro lado, como aponta Tsuru (2003), os depositantes não têm direito a quaisquer benefícios se um banco de elevado risco for bem-sucedido, mas poderão sofrer perdas no caso de falência bancária. Assim, devem contar com incentivos para reprimir as atividades de tomada excessiva de riscos por parte dos bancos.

Bliss e Flannery (2002) destacam os dois componentes da disciplina de mercado: monitorização e influência. A monitorização se refere à capacidade dos investidores avaliarem a real situação de uma entidade e enviar sinais de mercado para os gestores. Por seu lado, a influência descreve a capacidade de resposta dos gestores ao feedback dos investidores. O processo de disciplina de mercado não pode ser eficaz sem o primeiro.

Duas condições prévias devem ser satisfeitas para que os depositantes monitorizem com eficácia o risco bancário. A primeira é considerarem-se em risco. Nesse caso, não devem esperar nenhum apoio explícito ou implícito se o banco não conseguir gerir a situação de risco. A segunda pré-condição é que os depositantes devem processar corretamente a informação sobre o perfil de risco da entidade (CROCKETT, 2002). São necessários mercados financeiros transparentes para que a disciplina seja eficaz e permita que os depositantes tenham acesso, no momento certo, a informações relevantes, confiáveis, suficientes e de qualidade adequada (HAMALAINEN, HALL e HOWCROFT, 2005). Se os depositantes reconhecem os riscos bancários e reagem para ajustar as taxas e a disponibilidade de fundos de modo a reduzi-los, o mercado chegará à fase de influência. Nessa fase, os depositantes afetarão a instituição financeira direta e indiretamente (BLISS e FLANNERY, 2002), enviando sinais e fornecendo incentivos para que os bancos reduzam as atividades de risco, permitindo conter os problemas de um banco antes de espalharem-se pelo setor.

Foram promovidos inúmeros estudos para analisar a existência de disciplina de mercado, geralmente se concentrando mais nas reações dos detentores de dívida bancária, inclusive os depositantes. Os estudos utilizam abordagens baseadas no preço e na quantidade. Por exemplo, Cook e Spellman (1994) observaram uma relação positiva entre as taxas de depósitos não garantidos dos bancos americanos e o risco. Muitos outros estudos efetuaram esse tipo de análise e apoiam a existência de disciplina do depositante (JAGTIANI, KAUFMAN e LEMIEUX, 2000; GILBERT e VAUGHAN, 2001; WU e BOWE, 2012; ALANIS, BELADI e QUIJANO, 2015). Outro grupo de pesquisas analisa a retirada dos fundos pelos depositantes e conclui no mesmo sentido (p. ex., SHIMIZU, 2009; HASAN, JACKOWICZ, KOWALEWSKI et al., 2013; BERGER e TURK-ARISS, 2015; HOU, GAO e WANG, 2016). Um terceiro grupo de investigações combina 
ambas as abordagens (GHOSH e DAS, 2003; MAECHLER e MCDILL, 2006; UNGAN, CANER e ÖZYILDIRIM, 2008). A maioria analisa a disciplina em um único país, em especial os Estados Unidos da América (EUA), e em geral concluem que os depositantes são capazes de distinguir entre instituições fracas e instituições robustas e de mudar dos bancos mais arriscados para os bancos mais sólidos.

Se a maior parte das evidências empíricas parece sugerir que a disciplina de mercado é observada nos sistemas bancários desenvolvidos, sujeitos a requisitos de informação rigorosos, não é inteiramente claro que esteja sempre presente em economias emergentes, cujos sistemas de regulação e supervisão são relativamente fracos. Embora alguns estudos utilizem dados no nível de país (CALOMIRIS e POWELL, 2001; BARAJAS e STEINER, 2000; ROMERA e TABAK, 2010), as conclusões sobre a capacidade dos depositantes disciplinarem o risco bancário em mercados emergentes foram apoiadas, sobretudo, em investigações envolvendo vários países (MARTINEZ PERIA e SCHMUKLER, 2001; HOSONO, IWAKI e TSURU, 2004; DEMIRGÜÇKUNT e HUIZINGA, 2004; LEVY-YEYATI, MARTINEZ PERIA e SCHMUKLER, 2010). Esses estudos em âmbito nacional mostram que muitos países apresentam algum grau de disciplina do depositante, no entanto, o nível de tal disciplina depende da regulamentação bancária, do seguro de depósitos e do nível de desenvolvimento financeiro. Em geral, as análises concluem que a disciplina do depositante prevalece, mesmo com a existência de sistemas de garantia de depósitos, e destacam a importância dos fatores macroeconômicos, além dos fatores de risco bancário, nas decisões de retirada dos fundos. Ademais, a abordagem baseada na quantidade se mostra mais apropriada às economias em desenvolvimento devido a problemas de transparência e assimetria de informações nos mercados, o que faz com que as taxas sejam menos propensas a refletir informações sobre o risco bancário. Alguns estudos concluem que a disciplina de mercado se torna mais forte depois das crises (MARTINEZ PERIA e SCHMUKLER, 2001; HOSONO, IWAKI e TSURU, 2005), enquanto outros se concentram na importância da divulgação de informações confiáveis no incentivo à disciplina de mercado. Hasan, Jackowicz, Kowalewski et al. (2013) afirmam que, durante a crise financeira internacional, a reação dos depositantes em economias emergentes foi fortemente influenciada por rumores negativos da imprensa sobre as entidades financeiras. Fatores como a cultura dos depositantes e o nível de educação financeira também podem afetar as reações dos depositantes de modo diferente em cada país.

\section{O mercado bancário angolano}

Na última década, o setor bancário angolano registrou forte dinamismo, evidenciado pelos principais indicadores de desempenho, sendo acompanhado pelo reforço da "bancarização" da sociedade e do esforço de aproximação às normas bancárias internacionais. Segundo dados do Banco Nacional de Angola (BNA), relativos ao ano de 2018, o setor compreende 27 instituições financeiras bancárias autorizadas e em funcionamento, sendo 3 bancos públicos, 18 bancos privados nacionais e 6 filiais de bancos estrangeiros. As 5 maiores instituições representavam $68,8 \%$ dos ativos do setor. Da análise dos principais indicadores, destaca-se que, em termos de ativos totais, o setor registrou crescimento continuado e o agregado dos ativos correspondeu a $60 \%$ do produto interno bruto (PIB). A principal fonte de fundos consiste nos depósitos, sendo as captações para liquidez a segunda maior fonte de financiamento (Tabela 1); 1/4 dos 
depósitos consiste em moeda estrangeira. Além disso, sua estrutura de vencimentos ${ }^{1}$ indica que os depositantes preferem manter depósitos de curto prazo, cabendo ao segmento de empresas a posição mais relevante $(53,4 \%)$, seguido pelos particulares $(28,7 \%)$ e pelo setor público (16,7\%).

\section{TABELA 1}

\section{Evolução dos ativos e depósitos agregados 2008-2016 (em mil milhões de AKZ)}

\begin{tabular}{|c|c|c|c|c|c|c|c|c|c|}
\hline Designação & 2008 & 2009 & 2010 & 2011 & 2012 & 2013 & 2014 & 2015 & 2016 \\
\hline $\begin{array}{l}\text { Total de ativos } \\
\text { dos bancos }\end{array}$ & $2.680,7$ & $3.435,4$ & $4.114,8$ & $5.114,3$ & $5.900,3$ & $6.634,4$ & $7.106,1$ & $8.395,7$ & $8.721,2$ \\
\hline $\begin{array}{l}\text { Total de } \\
\text { depósitos } \\
\text { bancários }\end{array}$ & $1.427,9$ & $2.304,9$ & $2.710,4$ & $3.643,6$ & $3.973,5$ & $4.637,5$ & $5.352,4$ & $6.093,8$ & $6.387,4$ \\
\hline $\begin{array}{l}\text { Total de } \\
\text { depósitos/total } \\
\text { de ativos (\%) }\end{array}$ & 53,2 & 67 & 65,8 & 71,2 & 67,3 & 69,9 & 75,3 & 72,5 & 73,2 \\
\hline $\begin{array}{l}\text { Depósitos a } \\
\text { prazo/depósitos } \\
\text { totais (\%) }\end{array}$ & & 29,6 & 40,7 & 43,1 & 46,8 & 46 & 44 & 42,2 & 44,5 \\
\hline $\begin{array}{l}\text { Peso do crédito } \\
\text { no ativo total (\%) }\end{array}$ & 29,9 & 37,8 & 43,6 & 40,9 & 40 & 43,2 & 44 & 41,7 & 41 \\
\hline $\begin{array}{l}\text { Taxa de } \\
\text { transformação } \\
\text { (\%) }\end{array}$ & & 56,4 & 55,4 & 51,7 & 59,7 & 58,5 & 49,7 & 46,7 & 47,9 \\
\hline
\end{tabular}

Fonte: Elaborada pelo autor.

Nota: $A K Z=$ Kuanza de Angola (moeda).

A taxa de transformação do setor vem diminuindo, o que significa que, em termos médios, por cada kwanza captado sob a forma de depósitos, as instituições bancárias concedem menos crédito. Essa redução pode estar relacionada ao maior escrutínio na avaliação do risco e ao ciclo negativo da economia angolana a partir de 2014.

O setor apresenta duas características notórias. Primeira, apesar de haver um número razoável de bancos, o mercado é concentrado, sendo as 5 maiores entidades responsáveis por mais de $71 \%$ dos depósitos. Segunda, enquanto a taxa de poupança é alta, as políticas e práticas dos empréstimos bancários são arriscadas e estão tipicamente concentradas em poucos setores. Assim, a qualidade dos ativos é um dos aspectos críticos da banca angolana (Tabela 2), agravada a partir de 2014, com a degradação das condições monetárias e financeiras. Para mitigar os efeitos do aumento do não cumprimento, o setor teve de constituir provisões significativas de valor, mas não evitou a ocorrência de desequilíbrios ${ }^{2}$.

1 Os depósitos a prazo com maturidades inferiores a 1 ano representavam, em 2015, 93,6\% do total de depósitos a prazo.

${ }^{2}$ O Banco Espírito Santo Angola (BESA), cujo ativo transitou para o Banco Económico, foi forçado a encerrar em 2014 na sequência do colapso do Banco Espírito Santo (BES) português, seu principal acionista, e da avultada carteira de crédito em não cumprimento (4.755 milhões de euros). Posteriormente, em 2015, o Banco de Poupança e Crédito (BPC), um dos maiores bancos angolanos, do Estado, teve 
TABELA 2

Indicadores de Desempenho do setor bancário angolano (2010-2017)

\begin{tabular}{|lllllllll}
\hline Indicador (\%) & $\mathbf{2 0 1 0}$ & $\mathbf{2 0 1 1}$ & $\mathbf{2 0 1 2}$ & $\mathbf{2 0 1 3}$ & $\mathbf{2 0 1 4}$ & $\mathbf{2 0 1 5}$ & $\mathbf{2 0 1 6}$ & $\mathbf{2 0 1 7}$ \\
\hline $\begin{array}{l}\text { Solvabilidade: FPB (nível 1) /APR } \\
\text { Qualidade do ativo: crédito vencido / }\end{array}$ & 17,9 & 14,2 & 13,6 & 14,3 & 13,8 & 13,8 & 14,3 & 17,6 \\
\hline $\begin{array}{l}\text { crédito total } \\
\text { Rentabilidade: }\end{array}$ & 8,6 & 2,4 & 6,3 & 9,8 & 11,6 & 11,6 & 13,1 & 28,8 \\
\hline ROA & & & & & & & & \\
ROE & 3,0 & 2,6 & 1,6 & 1,4 & 0,64 & 1,7 & 2,2 & 2,1 \\
\hline CTI & 32,1 & 21,6 & 12,5 & 10,9 & 4,9 & 12,9 & 15,6 & 14,5 \\
\hline Taxa de depósitos da poupança & 39,2 & 41,0 & 48,5 & 53,7 & 58,7 & 47,4 & 45,2 & 51,8 \\
\hline Spread: taxa de empréstimos - taxa DO & 1,7 & 8,6 & 7,0 & 4,1 & 4,92 & 3,5 & 4,8 & 9,7 \\
\hline $\begin{array}{l}\text { Margem financeira / Margem bruta de } \\
\text { intermediação }\end{array}$ & 68,2 & 9,1 & 13,3 & 13,9 & 14,9 & 9,9 & 19,3 & 23,8 \\
\hline Liquidez: ativo líquido / ativo total & 32,0 & 28,1 & 26,3 & 30,1 & 33,8 & 39,7 & 46,3 & 33,8 \\
\hline Número de bancos & 20 & 22 & 22 & 22 & 23 & 28 & 27 & 29 \\
\hline
\end{tabular}

Fonte: Elaborada pelo autor.

Legenda: $\mathrm{FPB}=$ fundos próprios de base; $\mathrm{APR}=$ ativos ponderados pelo risco; $\mathrm{ROA}=$ return on assets; $\mathrm{ROE}=$ return on equity; $\mathrm{CTI}=$ cost-to-income; $\mathrm{DO}=$ depósitos à ordem.

O setor exibe fundos próprios suficientes para suportar os riscos econômicos e financeiros, apesar da tendência de diminuição da taxa, porém, 5 entidades apresentavam, em 2016, taxas de solvabilidade abaixo do mínimo regulamentar (10\%).

$\mathrm{O}$ regulador tem adotado vários procedimentos para reorganizar as operações dos bancos e ajustá-las aos requisitos do Acordo Basileia II, designadamente em termos de regras de divulgação, embora sob uma perspectiva regulatória se coloquem vários problemas, em particular a capacidade das instituições para fornecer informações precisas ao mercado.

Outra questão que permanece em aberto é a existência de um regime de seguro de depósitos. Apesar de consagrado legalmente há vários anos, o Fundo de Garantia de Depósitos (FGD) nunca chegou a ser instituído em Angola, persistindo a garantia implícita que é, por natureza, ex post, ad hoc e mal definida, com falta de clareza sobre quais passivos são cobertos e em quais circunstâncias.

de submeter-se a um plano de recapitalização e reestruturação, em consequência do nível de não cumprimento da sua carteira de crédito (estimada em 4.300 milhões de euros). Essa circunstância obrigou a constituição de expressivas imparidades e provisões, refletindo-se em elevados resultados negativos. Em 2018, o BNA adotou medidas de saneamento do Banco Angolano de Negócios e Comércio (BANC), devido à incapacidade dos acionistas promoverem o obrigatório aumento de capital, sendo-lhe posteriormente retirada a licença para operar como banco. 


\section{Metodologia}

Este estudo incluiu as duas abordagens referidas na literatura - quantidades e taxas de juros dos depósitos - para avaliar se os depositantes angolanos são capazes de monitorizar os riscos, captados a partir de indicadores de base contabilística, e penalizar as instituições mais arriscadas. Traduzem-se nas seguintes equações de regressão linear:

$$
\begin{gathered}
\operatorname{Var} \text { Dep }_{i, t}=\lambda_{0}+\sum_{j=1}^{m} \lambda_{j} \text { Risco }_{i, j, t-1}+\sum_{k=m+1}^{n} \lambda_{k} \text { Controle }_{i, k, t}+\omega_{i, t} \\
R_{i, t}=\beta_{0}+\sum_{j=1}^{m} \beta_{j} \text { Risco }_{i, j, t-1}+\sum_{k=m+1}^{n} \beta_{k} \text { Controle }_{i, k, t}+\omega_{i, t}
\end{gathered}
$$

As variáveis dependentes, $\operatorname{Var} \operatorname{Dep}_{i, t}$ e $R_{i, t}$, representam a variação do montante dos depósitos (medida pelo logaritmo do quociente entre os saldos dos depósitos de 2 períodos sucessivos) e a taxa de juros desses depósitos (taxa implícita resultante de dividir os gastos com juros pelos saldos médios dos depósitos), respectivamente, em que $t$ e $i$ indicam o período de tempo (ano) e a entidade bancária. As variáveis Risco $_{i, j, t-1}$ representam o risco bancário, sendo o vetor constituído por 5 indicadores (Tabela 3) que traduzem o grau de exposição. Apresentam defasagem de um período em relação à variável a explicar, para capturar o tempo que decorre até que as informações contabilísticas dos bancos sejam disponibilizadas e absorvidas pelos participantes do mercado. Destinam-se a capturar 3 aspectos essenciais do risco bancário: o risco de crédito, medido pela qualidade dos ativos; o risco de insolvência, medido pela taxa de capital e pelo indicador de rentabilidade bancária; e o risco de liquidez, medido pela proporção dos ativos líquidos no total do ativo. Além dos fatores de risco, adiciona-se uma medida da eficiência do banco ${ }^{3}$.

TABELA 3

\begin{tabular}{|c|c|c|c|}
\hline \multirow{2}{*}{ Variável } & \multirow{2}{*}{ Designação } & \multicolumn{2}{|c|}{ Sinal esperado do coeficiente } \\
\hline & & Modelo (1) & Modelo (2) \\
\hline Taxa de capital & $S O L V_{i, t}=\frac{C P P_{i, t}}{\text { Total.Ativo }_{i, t}}$ & + & - \\
\hline Taxa de imparidades & $I M P_{i, t}=\frac{\text { I.mparidades }_{i, t}}{\text { Total.Crédito }_{i, t}}$ & - & + \\
\hline Taxa de eficiência & $E f_{i, t}=\frac{\text { Custos. Operacionais }_{i, t}}{\text { Produto.Bancário }_{i, t}}$ & - & + \\
\hline
\end{tabular}

\section{Variáveis de risco e sinais esperados}

${ }^{3}$ As variáveis constituem a metodologia CAMEL, que resume a condição financeira das instituições a 5 dimensões: adequação de capital; qualidade dos ativos; qualidade de gestão; rentabilidade; e risco de liquidez. 
Taxa de rentabilidade

$$
R O A_{i, t}=\frac{R A I_{i, t}}{\text { Total.Ativo }}
$$

Taxa de liquidez

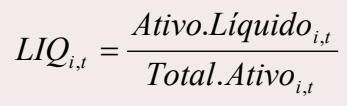

Fonte: Elaborada pelo autor.

As equações incluem, ainda, variáveis de controle (Controle $\left.{ }_{i, k, t}\right)$, pois o comportamento dos depósitos pode ser condicionado por fatores associados às condições econômicas e sistêmicas ou as características específicas dos bancos passíveis de influenciar sua trajetória. As variáveis sistêmicas consideradas refletem a evolução média dos saldos dos depósitos (DTSB $B_{t}$ e as taxas médias pagas pelo setor $\left(T M D S B_{t}\right)$. Alguns autores também incluem o controle da dimensão do banco (proxy do total do ativo), tendo em vista testar se os depositantes respondem ao efeito "too big to fail" (BERGER e TURK-ARISS, 2015). Assim, a variável Ativo ${ }_{i, t}$ tem em vista controlar se os depósitos são afetados pelo tamanho da instituição. Para apreender a qualidade dos serviços prestados aos depositantes, introduz-se uma variável do nível dos serviços de transações bancárias, utilizando para o efeito o número de agências como proxy $\left(A g_{i, t}\right)$. Finalmente, o comportamento dos depósitos também pode ser influenciado pelo estado da economia. Controla-se os efeitos dos choques macroeconômicos e a força relativa da economia, que afetam todos os bancos de forma igual, a partir das variáveis taxa de crescimento do produto interno bruto $\left(P I B_{t}\right)$ e taxa de inflação medida pela alteração no índice de preços ao consumidor ( Infl).

Em um segundo momento, à especificação inicialmente definida são acrescidas variáveis de controle relacionadas a propriedade $\left(P O P_{i, t}\right)$ e origem do capital $\left(O R_{i, t}\right)$. Para a propriedade do capital, insere-se uma variável dummy que assume o valor 1 se um banco é privado e 0 no caso contrário (público), e uma segunda dummy que assume o valor 1 se um banco é propriedade de estrangeiros e 0 no caso de acionistas nacionais. Sua inclusão visa a testar se os depositantes percebem os bancos públicos como mais propensos a ser apoiados e se os bancos estrangeiros têm alguma vantagem reputacional diante dos concorrentes domésticos.

\section{Amostra e dados}

A amostra é constituída por todos os bancos que operavam em Angola dentro do período do estudo para os quais há dados disponíveis. Inclui 28 entidades e abrange o período de 2008 a 2017. Os dados em painel são construídos utilizando os relatórios e as contas auditados que as instituições divulgam publicamente em uma base anual. Como o estudo se concentra na monitorização pelo mercado, que é uma análise ex ante, seria preferível uma maior frequência de observações, contudo, não há dados completos com frequência trimestral ou base semestral. Os dados são não balanceados, pois o número de observações por banco varia ao longo dos 
anos. Durante o período da amostra houve entrada de novos bancos no mercado e saídas. A amostra integra 3 bancos públicos, 6 bancos estrangeiros e 19 bancos privados nacionais.

A Tabela 4 apresenta o resumo das estatísticas descritivas. Sua principal utilidade é indicar o grau de heterogeneidade das reações do mercado aos riscos bancários (crescimento dos depósitos e taxas de juros) e descrever as variações médias ao longo do tempo das diversas medidas de risco.

A taxa de solvabilidade apresenta valores médios da ordem de $15,4 \%$ e os bancos apresentam níveis de liquidez elevados (em média, cerca de $37 \%$ em relação aos seus ativos totais). Vale destacar, ainda, a rentabilidade, expressa no retorno médio sobre os ativos de $0,86 \%$, possivelmente estimulada pelos elevados spreads das taxas de juros.

TABELA 4

Estatísticas descritivas (2008-2017)

\begin{tabular}{|c|c|c|c|c|c|c|c|}
\hline Variável & Média & Mediana & Desvio padrão & Máximo & Mínimo & $\begin{array}{l}\text { Número de } \\
\text { observações }\end{array}$ & $\begin{array}{l}\text { ADF } \\
\text { (nível) }\end{array}$ \\
\hline$R_{i, t}$ & 2.39 & 1.98 & 1.80 & 11.29 & $1.53 \mathrm{E}-03$ & 187 & $\begin{array}{r}-24,2351 \\
(0,0000)\end{array}$ \\
\hline $\operatorname{VarDep}_{i, t}$ & 32.53 & 21.84 & 46.61 & 259.13 & -90.35 & 193 & $\begin{array}{r}-26,2597 \\
(0,0000)\end{array}$ \\
\hline $\operatorname{VarDP} P_{i, t}$ & 39,75 & 20,51 & 105,15 & 624,52 & $-299,96$ & 164 & $\begin{array}{l}-7,1996 \\
(0,0000)\end{array}$ \\
\hline$A C_{i, t-1}$ & 15.41 & 11.57 & 12.15 & 79.76 & -21.40 & 192 & $\begin{array}{c}-15,7528 \\
(0,0000)\end{array}$ \\
\hline$I M P_{i, t-1}$ & 10.07 & 4.67 & 20.53 & 116.15 & 0.00 & 188 & $\begin{array}{l}-8,2789 \\
(0,0000)\end{array}$ \\
\hline$E f_{i, t-1}$ & 52.40 & 108.38 & 1981.03 & 20120,35 & -70.57 & 194 & $\begin{array}{r}-13,7138 \\
(0,0000)\end{array}$ \\
\hline$R O A_{i, t-1}$ & 0.86 & 2.38 & 9.49 & -66.69 & 24.98 & 194 & $\begin{array}{c}-8,9714 \\
(0,0000)\end{array}$ \\
\hline$L I Q_{i, t-1}$ & 36.97 & 32.32 & 19.89 & 152.99 & 3.20 & 194 & $\begin{array}{r}-17,1498 \\
(0,0000)\end{array}$ \\
\hline Ativo $_{i, t}$ & 10,24 & 10,37 & 1,60 & 13,37 & 4,86 & 194 & \\
\hline$A g_{\cdot i, t}$ & 65,63 & 26 & 82,22 & 443 & 1 & 179 & \\
\hline$T M D S B_{t}$ & 6.74 & 5.24 & 3.07 & 12.59 & 3.87 & 194 & \\
\hline$D T S B_{t}$ & 4.057 & 3.620 & 1.529 & 6.387 & 1.427 & 179 & \\
\hline Infl $t_{t}$ & 16.55 & 13.18 & 11.00 & 41.95 & 7.48 & 194 & \\
\hline$P I B_{t}$ & 4.50 & 3.90 & 3.24 & 13.80 & 1.10 & 194 & \\
\hline
\end{tabular}

Fonte: Elaborada pelo autor.

Notas:

- Os números na tabela estão em percentagens, exceto o Ativo (LN Ativo Total), o número de agências e os depósitos do setor (mil miIhões de kwanzas). Os dados das variáveis macroeconômicas foram retiradas do banco de dados do Banco Nacional de Angola (BNA). - O ADF é o teste Augmented Dickey Fuller para a estacionaridade (DICKEY e FULLER, 1979). O objetivo básico desse teste é analisar a hipótese nula de que a série contém uma raiz unitária versus a hipótese alternativa de que a série é estacionária. Para incluir a variável nos modelos deve ser obtida a condição de estacionaridade. Os resultados indicam que as variáveis são estacionárias em seus níveis. 
A proporção de empréstimos em relação ao ativo se situa em valores relativamente modestos (27\%) e os níveis de provisões para perdas se mostram baixos nos primeiros anos, reforçando-se acentuadamente no decorrer do período de amostragem, fixando-se a média acima de 10\% do total da carteira.

\section{Resultados e discussão}

\section{Reação do depositante ao risco bancário: crescimento dos depósitos}

As estimativas para a equação (1) do crescimento dos depósitos são apresentadas na Tabela 5. A variável dependente regrediu contra as variáveis de risco bancário, variáveis específicas não associadas a indicadores de risco e variáveis macroeconômicas e sistêmicas. Nas equações numeradas de 1 a 5, as variáveis de risco são incluídas, mas apenas uma de cada vez. A equação 6 agrega a totalidade. O objetivo é ver se as equações confirmam a influência individual sobre o crescimento dos depósitos quando comparadas com sua combinação global.

\section{TABELA 5}

Crescimento dos depósitos e risco bancário (2008-2017)

\begin{tabular}{|c|c|c|c|c|c|c|c|}
\hline \multirow{2}{*}{$\begin{array}{l}\text { Variáveis } \\
\text { Risco e } \\
\text { Controle }\end{array}$} & \multicolumn{6}{|c|}{ Variável dependente: crescimento dos depósitos (Vardepit) } & \multirow{2}{*}{$\begin{array}{c}\text { VarDPit } \\
\text { (7) }\end{array}$} \\
\hline & (1) & (2) & (3) & (4) & (5) & (6) & \\
\hline$A C_{i, t-1}$ & $\begin{array}{c}1.8736^{* * *} \\
(6.5141)\end{array}$ & & & & & $\begin{array}{r}1.4176^{* * *} \\
(4.0663)\end{array}$ & $\begin{array}{c}2.3461^{* *} \\
(2.5072)\end{array}$ \\
\hline$I M P_{i, t-1}$ & & $\begin{array}{c}-0.2447 \\
(-0.5025)\end{array}$ & & & & $\begin{array}{c}-0.0729 \\
(-0.1831)\end{array}$ & $\begin{array}{c}0,2631 \\
(0,4878)\end{array}$ \\
\hline$E f_{i, t-1}$ & & & $0.0054^{* * *}$ & & & $\begin{array}{c}0.0010 \\
(0.2523)\end{array}$ & $\begin{array}{r}-2.03 E-06 \\
(-0.0003)\end{array}$ \\
\hline$R O A_{i, t-1}$ & & & & $\begin{array}{c}-0.1473 \\
(-0.2330)\end{array}$ & & $\begin{array}{c}-0.8672^{* *} \\
(-1.9980)\end{array}$ & $\begin{array}{c}0.4831 \\
(0,4132)\end{array}$ \\
\hline$L I Q_{i, t-1}$ & & & & & $\begin{array}{c}0.0832 \\
(0.4253)\end{array}$ & $\begin{array}{c}-0.0122 \\
(-0.0781)\end{array}$ & $\begin{array}{c}0.4576 \\
(0.8448)\end{array}$ \\
\hline Ativo $_{i, t}$ & $\begin{array}{c}0.0324 \\
(1.1690)\end{array}$ & $\begin{array}{c}-0.0458^{* *} \\
(-2.2721)\end{array}$ & $\begin{array}{c}-0.0255 \\
(-0.9045)\end{array}$ & $\begin{array}{c}0.0153 \\
(0.2422)\end{array}$ & $\begin{array}{l}-0.0479^{*} \\
(-1.6783)\end{array}$ & $\begin{array}{l}0.0486^{* *} \\
(2.3914)\end{array}$ & $\begin{array}{l}0.0823^{*} \\
(1.8567)\end{array}$ \\
\hline Agências $_{i, t}$ & $\begin{array}{c}-0.0010^{* *} \\
(-2.2537)\end{array}$ & $\begin{array}{c}-0.0010^{* * *} \\
(-3.0143)\end{array}$ & $\begin{array}{c}-0.0011^{* *} \\
(-2.1344)\end{array}$ & $\begin{array}{l}-0.0007 \\
(-0.7078)\end{array}$ & $\begin{array}{l}-0.0010^{*} \\
(-1.8067)\end{array}$ & $\begin{array}{c}-0.0012^{* *} \\
(-2.3956)\end{array}$ & $\begin{array}{c}-0.0007 \\
(-0.5559)\end{array}$ \\
\hline$D T S B_{t}$ & $\begin{array}{c}-7.17 \mathrm{E}-08^{* *} \\
(-2.5550)\end{array}$ & $\begin{array}{r}-7.29 \mathrm{E}-08^{*} \\
(-2.0513)\end{array}$ & $\begin{array}{c}-7.34 \mathrm{E}- \\
08^{* *} \\
(-2.4518)\end{array}$ & $\begin{array}{c}-1.21 \mathrm{E}- \\
07^{* *} \\
(-2.2909)\end{array}$ & $\begin{array}{c}-6.69 \mathrm{E}- \\
08^{* *} \\
(-2.1224)\end{array}$ & $\begin{array}{c}-8.21 \mathrm{E}- \\
08^{* * *} \\
(-3.5988)\end{array}$ & $\begin{array}{c}-2.03 \mathrm{E}- \\
07^{* *} \\
(-2.5705)\end{array}$ \\
\hline
\end{tabular}




\begin{tabular}{|c|c|c|c|c|c|c|c|}
\hline \multirow{2}{*}{$\begin{array}{l}\text { Variáveis } \\
\text { Risco e } \\
\text { Controle }\end{array}$} & \multicolumn{6}{|c|}{ Variável dependente: crescimento dos depósitos (Vardepit) } & \multirow{2}{*}{$\begin{array}{c}\text { VarDPit } \\
\text { (7) }\end{array}$} \\
\hline & (1) & (2) & (3) & (4) & (5) & (6) & \\
\hline Infl $_{t}$ & $\begin{array}{l}0.6721^{*} \\
(1.9221)\end{array}$ & $\begin{array}{l}0.3814^{*} \\
(1.8273)\end{array}$ & $\begin{array}{l}0.6531^{*} \\
(1.7689)\end{array}$ & $\begin{array}{c}0.0091 \\
(0.0335)\end{array}$ & $\begin{array}{c}0.6883^{*} \\
(1.7946)\end{array}$ & $\begin{array}{c}0.4805 \\
(1.2814)\end{array}$ & $\begin{array}{c}1.4733 \\
(1.5529)\end{array}$ \\
\hline$P I B_{t}$ & $\begin{array}{c}-0.4945 \\
(-0.3871)\end{array}$ & $\begin{array}{c}-1.0477 \\
(-0.7557)\end{array}$ & $\begin{array}{c}-0.9702 \\
(-0.7106)\end{array}$ & $\begin{array}{c}-1.3022 \\
(-0.7879)\end{array}$ & $\begin{array}{c}-0.8383 \\
(-0.5911)\end{array}$ & $\begin{array}{c}-0.5316 \\
(-0.2943)\end{array}$ & $\begin{array}{l}-7.1881^{* *} \\
(-2.1210)\end{array}$ \\
\hline $\begin{array}{l}\text { Número de } \\
\text { bancos }\end{array}$ & 28 & 25 & 28 & 28 & 28 & 25 & 25 \\
\hline Observações & 168 & 164 & 168 & 168 & 168 & 164 & 150 \\
\hline $\begin{array}{l}\text { Estimador } \\
\text { (tipo) }\end{array}$ & EGLS EA & EGLS EA & EGLS EA & PLS & EGLS EA & PLS & PLS \\
\hline$R_{\text {Ajustado }}^{2}$ & 0.2878 & 0.1142 & 0.1684 & 0.3284 & 0.1160 & 0.2484 & 0,0626 \\
\hline $\begin{array}{l}F-\text { Statisc } \\
(\text { valor }-p)\end{array}$ & $\begin{array}{l}12.2515 \\
(0,0000)\end{array}$ & $\begin{array}{c}4.5044 \\
(0,0003)\end{array}$ & $\begin{array}{c}6.6396 \\
(0,0000)\end{array}$ & $\begin{array}{c}3.4754 \\
(0,0000)\end{array}$ & $\begin{array}{c}4.6558 \\
(0,0002)\end{array}$ & & \\
\hline
\end{tabular}

Fonte: Elaborada pelo autor.

Notas:

- EGLS EA = Estimated Generalized Least Square - Efeitos Aleatórios (método de regressão utilizado no caso de problemas de heterocedasticidade ou auto-regressão).

- PLS = Panel Least Squares

- A constante não é reportada, embora possa constar das regressões.

- São reportados estimadores sem e com efeitos fixos e aleatórios. As estatísticas $t$ estão entre parênteses.

- Foram obtidos erros padrão robustos utilizando white standard errors \& covariance (d.f. corrected) para a heterocedasticidade.

_****** $\mathrm{e}^{*}$ indicam os níveis de significância de $1 \%, 5 \%$ e $10 \%$, respectivamente.

Em termos gerais, os resultados observados mostram evidências pouco conclusivas sobre a eficácia da disciplina do depositante. Vale a pena notar o limitado valor do coeficiente de determinação no teste ao conjunto das variáveis de risco: 24,8\% (a capacidade explicativa do modelo é 13,5\% sem controlar as condições sistêmicas e macroeconômicas). Além disso, a maioria das variáveis de risco se insere na equação de crescimento dos depósitos de modo inconsistente com a hipótese de existência de disciplina. A variável explicativa mais robusta é a taxa de capital, indicando que os depositantes consideram os níveis de solvabilidade na escolha dos bancos. O sinal do coeficiente da variável provisões e imparidades (IMP) apoia a conclusão de que os depositantes em Angola penalizam os bancos de menor qualidade, retirando seus fundos, contudo, a relação é estatisticamente pouco significativa. A mesma ausência de significado estatístico é observada na eficiência de gestão $(E f)$, cujo coeficiente sugere que as práticas de gestão ineficientes não afetam negativamente o crescimento dos depósitos. Já a variável retorno sobre os ativos (return on assets - ROA) é significativa no nível de 5\%, quer na equação individual $(-0,1473)$, quer no modelo completo, e expressa uma relação negativa com o crescimento dos depósitos (os bancos mais rentáveis não conseguem atrair mais depósitos). No tocante à liquidez, a equação individual indica que os bancos com relativamente mais ativos líquidos experimentam um aumento em sua base de depósitos (coeficiente positivo de 0,0832), mas se trata de uma relação baixa em termos de significância estatística.

Algumas variáveis de controle se mostram relevantes para explicar o crescimento dos depósitos. O tamanho do banco apresenta um coeficiente positivo $(0,0486)$, indicando que, 
ceteris paribus, os bancos maiores captam mais depósitos. Esse relacionamento entre o tamanho da instituição e a variação dos depósitos é consistente com outros estudos (p. ex., MAECHLER e MCDILL, 2006), que concluíram que a dimensão dos bancos ajuda a atrair depósitos. De igual forma, a expansão da rede bancária aparece associada ao aumento dos depósitos como resultado do alargamento da base de captação. Finalmente, a evolução do conjunto do setor é uma variável explicativa com significado estatístico, evidenciando que o crescimento dos depósitos das instituições integrantes da amostra acompanha a tendência geral. Embora o nível de inflação afete positivamente o comportamento dos depósitos, seu significado estatístico é modesto, tal como sucede com a taxa de crescimento do PIB. Além disso, o sinal indica que, ceteris paribus, a taxa de crescimento econômico não contribui para aumentar a disposição do público para elevar os depósitos bancários. Até certo ponto, esse resultado é surpreendente porque se esperaria que quanto melhor fosse o estado da economia, maior seria a procura por depósitos. A relação observada talvez possa ser explicada pela disponibilidade para substituir os depósitos por outras opções de investimento em períodos de otimismo econômico.

Os testes incluíram, ainda, a distinção entre 2 medidas de depósitos, depósitos totais e depósitos a prazo. Os resultados (Tabela 5, coluna 7) não mostram evidências de distintos graus de disciplina entre os 2 grupos de depósitos. A exclusão dos depósitos à ordem, instrumentos monetários que, a priori, são relativamente mais insensíveis ao risco, não se traduziu em maior acentuação do efeito disciplinar dos depósitos a prazo.

\section{Risco bancário e taxas de depósitos}

A Tabela 6 resume os resultados das estimativas para a equação das taxas de juros. É identificada uma fraca relação entre a variável a explicar e os indicadores de risco selecionados, não se observando provas diretas de que a disciplina dos depositantes afete significativamente a remuneração dos depósitos bancários.

\section{TABELA 6}

Taxa de juros dos depósitos e risco bancário (2008-2017)

\begin{tabular}{|c|c|c|c|c|c|c|}
\hline \multirow{2}{*}{$\begin{array}{l}\text { Variáveis } \\
\text { Risco e } \\
\text { Controle }\end{array}$} & \multicolumn{6}{|c|}{ Dependente: taxa de juros dos depósitos $\left(\boldsymbol{R}_{i, t}\right)$} \\
\hline & (1) & (2) & (3) & (4) & (5) & (6) \\
\hline$A C_{i, t-1}$ & $\begin{array}{c}0.0419^{* *} \\
(2.1898)\end{array}$ & & & & & $\begin{array}{c}0.0115 \\
(0.6865)\end{array}$ \\
\hline$I M P_{i, t-1}$ & & $\begin{array}{c}0.0003 \\
(0.0736)\end{array}$ & & & & $\begin{array}{c}0.0050 \\
(0.8212)\end{array}$ \\
\hline$E f_{i, t-1}$ & & & $\begin{array}{l}4.07 E-06 \\
(0.0962)\end{array}$ & & & $\begin{array}{c}0.0001 \\
(1.0892)\end{array}$ \\
\hline$R O A_{i, t-1}$ & & & & $\begin{array}{c}-0.0151 \\
(-1.1037)\end{array}$ & & $\begin{array}{c}0.0134 \\
(0.5002)\end{array}$ \\
\hline$L I Q_{i, t-1}$ & & & & & $\begin{array}{c}-0.0171^{* * *} \\
(-2.7350)\end{array}$ & $\begin{array}{c}-0.0117 \\
(-1.5433)\end{array}$ \\
\hline
\end{tabular}




\begin{tabular}{|c|c|c|c|c|c|c|}
\hline \multirow{2}{*}{$\begin{array}{l}\text { Variáveis } \\
\text { Risco e } \\
\text { Controle }\end{array}$} & \multicolumn{6}{|c|}{ Dependente: taxa de juros dos depósitos $\left(\boldsymbol{R}_{i, t}\right)$} \\
\hline & (1) & (2) & (3) & (4) & (5) & (6) \\
\hline Ativo $_{i, t}$ & $\begin{array}{c}-0.0024 \\
(-1.4337)\end{array}$ & $\begin{array}{c}0.0005 \\
(1.0063)\end{array}$ & $\begin{array}{c}0.0004 \\
(0.9941)\end{array}$ & $\begin{array}{c}-0.0027 \\
(-1.2988)\end{array}$ & $\begin{array}{c}-0.0005 \\
(-0.4375)\end{array}$ & $\begin{array}{c}-0.0027^{* * *} \\
(-2.8457)\end{array}$ \\
\hline Agências $_{i, t}$ & $\begin{array}{c}2.17 \mathrm{E}-05 \\
(0.3626)\end{array}$ & $\begin{array}{c}6.03 \mathrm{E}-05^{* * *} \\
(4.1612)\end{array}$ & $\begin{array}{c}6.35 \mathrm{E}-05^{* * *} \\
(4.4272)\end{array}$ & $\begin{array}{c}3.51 \mathrm{E}-05 \\
(0.7401)\end{array}$ & $\begin{array}{c}6.01 \mathrm{E}-05^{* *} \\
(2.4703)\end{array}$ & $\begin{array}{c}9.52 \mathrm{E}-05^{* * *} \\
\quad(5.6468)\end{array}$ \\
\hline$T M D S B_{t}$ & $\begin{array}{c}0.0672 \\
(1.1420)\end{array}$ & $\begin{array}{c}0.1614^{* * *} \\
(3.5433)\end{array}$ & $\begin{array}{c}0.1637^{* * *} \\
(3.6157)\end{array}$ & $\begin{array}{c}0.0776 \\
(1.3561)\end{array}$ & $\begin{array}{c}0.1199 * * * \\
(3.1833)\end{array}$ & $\begin{array}{c}0.4608^{* * *} \\
(2.8294)\end{array}$ \\
\hline $\mathrm{Infl}_{t}$ & $\begin{array}{c}0.0114 \\
(1.1457)\end{array}$ & $\begin{array}{c}0.0033 \\
(0.2987)\end{array}$ & $\begin{array}{c}0.0001 \\
(0.0125)\end{array}$ & $\begin{array}{c}0.0049 \\
(0.4208)\end{array}$ & $\begin{array}{c}-0.0024 \\
(-0.2370)\end{array}$ & $\begin{array}{c}0.0334^{* * *} \\
(2.6994)\end{array}$ \\
\hline$P I B_{t}$ & $\begin{array}{c}-0.0061 \\
(-0.1144)\end{array}$ & $\begin{array}{l}0.0512 \\
(0.7690)\end{array}$ & $\begin{array}{c}0.0510 \\
(0.7621)\end{array}$ & $\begin{array}{c}-0.0067 \\
(-0.1653)\end{array}$ & $\begin{array}{c}0.0235 \\
(0.6095)\end{array}$ & $\begin{array}{c}0.4157^{* * *} \\
(4.7895)\end{array}$ \\
\hline $\begin{array}{l}\text { Número de } \\
\text { bancos }\end{array}$ & 28 & 25 & 28 & 28 & 28 & 25 \\
\hline Observações & 176 & 171 & 177 & 177 & 177 & 171 \\
\hline Estimador & PLS EF & PLS & PLS & PLS EF & PEGLS EA & PLS \\
\hline$R_{\text {Ajustado }}^{2}$ & 0.4258 & 0.1223 & 0.1432 & 0.3971 & 0.1249 & 0.3704 \\
\hline $\begin{array}{l}F-\text { Statisc } \\
(\text { valor }-p)\end{array}$ & $\begin{array}{c}4.9337 \\
(0.0000)\end{array}$ & & & $\begin{array}{c}4.5131 \\
(0.0000)\end{array}$ & $\begin{array}{c}5.1902 \\
(0.0000)\end{array}$ & \\
\hline DW & 1,9055 & 2,1187 & 2,1318 & 1.9820 & 1,9405 & 2,224 \\
\hline
\end{tabular}

Fonte: Elaborada pelo autor.

Notas:

- São reportados estimadores sem e com efeitos fixos e aleatórios.

- A constante não é reportada, embora possa constar das regressões.

- As estatísticas $t$ estão entre parênteses. Foram obtidos erros padrão robustos utilizando white standard errors \& covariance (d.f. corrected) para a heterocedasticidade.

- ***** $\mathrm{e}^{*}$ indicam os níveis de significância de $1 \%, 5 \%$ e $10 \%$, respectivamente.

A taxa de solvabilidade $(A C)$ apenas se mostra relacionado positiva e significativamente aos juros pagos aos depositantes na equação individual. Além disso, o sinal observado se desvia do previsto - os depositantes recebem maiores taxas nos bancos mais capitalizados -, o que pode querer indicar que os bancos angolanos só aumentam o capital quando enfrentam maiores riscos. Quanto ao coeficiente da variável $L I Q$, depreende-se que os bancos com maior liquidez conseguem reduzir as despesas com juros. Por outro lado, os bancos com maiores níveis de imparidades (IMP) e melhores resultados (ROA) pagam juros mais elevados aos depositantes. Essa conexão talvez se justifique pelo fato dos bancos mais arriscados poderem gerar maiores lucros e, assim, oferecer taxas de juros mais competitivas (elevadas) aos depositantes, com a finalidade de manter os níveis de depósitos. Por fim, os bancos com maiores despesas não decorrentes dos juros, isto é, menos eficientes ( $E f$ ), pagam juros mais elevados aos depositantes, o que pode estar relacionado à sinalização de práticas de gestão ineficientes. Um resultado bem definido na Tabela 6 é que, na equação conjunta, as variáveis de risco bancário não conseguem explicar o comportamento das taxas de juros.

Entre as variáveis não fundamentais, a dimensão do ativo parece ter um efeito significativo sobre os juros pagos aos depositantes: os maiores bancos pagam menores taxas. Isso sugere que os depositantes percebem o tamanho da instituição como sinal de melhor condição financeira, 
embora o maior número de agências não seja suscetível de reduzir os juros pagos. As variáveis macroeconômicas são significativas, mas apenas o sinal do coeficiente da inflação é consistente com a teoria (taxas de juros maiores para compensar a perda de valor real dos depósitos). As taxas dos depósitos acompanham as condições médias do setor.

A robustez dos resultados foi testada com recurso a um estimador de dois passos e também mediante uma análise de painel dinâmica (GMM), controlando o efeito preço sobre o crescimento dos depósitos por inclusão da taxa de juros como variável exógena adicional ao modelo. As análises subsequentes confirmam que as variáveis de risco bancário explicam pouco o comportamento dos depósitos.

\section{Extensão da análise: proveniência e propriedade do capital}

Após inclusão de variáveis dummy, em função da proveniência do capital $(P R O P)$ e seu controle $(O C)$, os testes não confirmam esses fatores como explicativos de diferentes níveis de disciplina exercida pelos depositantes (Tabela 7).

O mecanismo baseado na quantidade parece ser utilizado da mesma forma por depositantes dos bancos privados e públicos. Estatisticamente, as escolhas dos depositantes não são determinadas pela propriedade do capital, contudo, o sinal positivo do coeficiente de PROP evidencia que os bancos públicos parecem mais confiáveis, possivelmente pelo fato de estarem associados a garantias do Estado. Da mesma forma, o mecanismo das taxas não é mais explícito para os bancos privados em comparação com os bancos públicos.

A reação dos depositantes de bancos estrangeiros não se distingue significativamente do comportamento dos depositantes de bancos nacionais, isto é, os depositantes parecem reagir de modo indiferente à origem do capital dos bancos. Os coeficientes dos regressores se mantêm praticamente inalterados em relação às estimativas anteriores, concluindo-se pela ausência de alterações decorrentes da introdução dessas variáveis, o que é um pouco decepcionante, pois era de esperar que a disciplina do depositante fosse estatisticamente diferente para os desiguais grupos de bancos.

\section{TABELA 7}

Origem e propriedade do capital

\begin{tabular}{|c|c|c|c|c|}
\hline \multirow{3}{*}{$\begin{array}{c}\text { Variáveis } \\
\text { Risco e Controle }\end{array}$} & \multicolumn{4}{|c|}{$2008-2017$} \\
\hline & \multicolumn{2}{|c|}{ Vardep $_{i, t}$} & \multicolumn{2}{|c|}{$\boldsymbol{R}_{i, t}$} \\
\hline & (1) & (2) & (3) & (4) \\
\hline$A C_{i, t-1}$ & $\begin{array}{c}1.5129^{* * * *} \\
(4.5044)\end{array}$ & $\begin{array}{c}1.4080^{* * * *} \\
(4.1754)\end{array}$ & $\begin{array}{c}0.0126 \\
(0.7471)\end{array}$ & $\begin{array}{c}0.0110 \\
(0.6905)\end{array}$ \\
\hline$I M P_{i, t-1}$ & $\begin{array}{c}-0.0783 \\
(-0.1943)\end{array}$ & $\begin{array}{c}-0.0748 \\
(-0.1826)\end{array}$ & $\begin{array}{c}0.0052 \\
(0.8581)\end{array}$ & $\begin{array}{c}0.0051 \\
(0.8638)\end{array}$ \\
\hline$E f_{i, t-1}$ & $\begin{array}{c}0.0007 \\
(0.2947)\end{array}$ & $\begin{array}{c}0.0010 \\
(0.4287)\end{array}$ & $\begin{array}{c}0.0001 \\
(1.0894)\end{array}$ & $\begin{array}{c}0.0001 \\
(1.1006)\end{array}$ \\
\hline
\end{tabular}




\begin{tabular}{|c|c|c|c|c|}
\hline \multirow{3}{*}{$\begin{array}{c}\text { Variáveis } \\
\text { Risco e Controle }\end{array}$} & \multicolumn{4}{|c|}{$2008-2017$} \\
\hline & \multicolumn{2}{|c|}{ Vardep $_{i, t}$} & \multicolumn{2}{|c|}{$R_{i, t}$} \\
\hline & (1) & (2) & (3) & (4) \\
\hline$R O A_{i, t-1}$ & $\begin{array}{l}-0.8248^{*} \\
(-1.9365)\end{array}$ & $\begin{array}{l}-0.8677^{* *} \\
(-2.0340)\end{array}$ & $\begin{array}{c}0.0136 \\
(0.5074)\end{array}$ & $\begin{array}{c}0.0133 \\
(0.4946)\end{array}$ \\
\hline$L I Q_{i, t-1}$ & $\begin{array}{c}0.0009 \\
(0.0047)\end{array}$ & $\begin{array}{l}-0.0106 \\
(-0.0545)\end{array}$ & $\begin{array}{c}-0.0117 \\
(-1.5532)\end{array}$ & $\begin{array}{l}-0.0118 \\
(-1.5464)\end{array}$ \\
\hline Ativo $_{i, t}$ & $\begin{array}{c}0.0500^{* * *} \\
(2.8688)\end{array}$ & $\begin{array}{l}0.0466^{* *} \\
(2.5194)\end{array}$ & $\begin{array}{l}-0.0024^{* *} \\
(-2.3446)\end{array}$ & $\begin{array}{c}-0.0027^{* * *} \\
(-2.8121)\end{array}$ \\
\hline Agências $_{i, t}$ & $\begin{array}{c}-0.0012^{* * *} \\
(-2.9232)\end{array}$ & $\begin{array}{l}-0.0011^{* *} \\
(-2.5781)\end{array}$ & $\begin{array}{c}8.53 \mathrm{E}-05^{* * *} \\
(4.0155)\end{array}$ & $\begin{array}{c}9.55 \mathrm{E}-05^{* * *} \\
(5.9731)\end{array}$ \\
\hline$D T S B_{t}$ & $\begin{array}{c}-8.44 \mathrm{E}-08^{* * *} \\
(-2.9138)\end{array}$ & $\begin{array}{c}-8.26 \mathrm{E}-08 \text { ** } \\
(-2.8733)\end{array}$ & & \\
\hline$T M D S B_{t}$ & & & $\begin{array}{c}0.4672^{* * * *} \\
(2.8041)\end{array}$ & $\begin{array}{c}0.4605^{* * *} \\
(2.8229)\end{array}$ \\
\hline $\operatorname{lnf} f_{t}$ & $\begin{array}{c}0.4886 \\
(1.1672)\end{array}$ & $\begin{array}{c}0.4782 \\
(1.1451)\end{array}$ & $\begin{array}{c}0.0339 * * * \\
(2.7442)\end{array}$ & $\begin{array}{c}0.0335^{* * *} \\
(2.6499)\end{array}$ \\
\hline$P I B_{t}$ & $\begin{array}{l}-0.6126 \\
(-0.4593)\end{array}$ & $\begin{array}{c}-0.5446 \\
(-0.4105)\end{array}$ & $\begin{array}{c}0.4195^{* * *} \\
(4.8599)\end{array}$ & $\begin{array}{c}0.4172^{* * *} \\
(4.6773)\end{array}$ \\
\hline$P R O B_{i, t}$ & & $\begin{array}{c}0.0217 \\
(0.2264)\end{array}$ & $\begin{array}{c}-0.0035 \\
(-0.7689)\end{array}$ & \\
\hline$O C_{i, t}$ & $\begin{array}{l}-0.0824 \\
(-1.0409)\end{array}$ & & & $\begin{array}{c}0.0005 \\
(0.1266)\end{array}$ \\
\hline Número de bancos & 25 & 25 & 21 & 21 \\
\hline Observações & 164 & 164 & 144 & 144 \\
\hline Estimador & PLS & PLS & PLS & PLS \\
\hline $\mathrm{R}_{\text {Ajustado }}^{2}$ & 0.2485 & 0.2436 & 0.3668 & 0.3658 \\
\hline DW & 1,83 & 1,82 & 2,23 & 2,22 \\
\hline
\end{tabular}

Fonte: Elaborada pelo autor.

Notas:

- São reportados apenas estimadores PLS.

- A constante não é reportada, embora possa constar das regressões.

- As estatísticas $t$ estão entre parênteses. Foram obtidos erros padrão robustos utilizando cross-section SUR (PCSE) standard errors \& covariance (d.f. corrected).

- ***** $\mathrm{e}^{*}$ indicam os níveis de significância de $1 \%, 5 \%$ e $10 \%$, respectivamente.

\section{Disciplina dos depositantes e crise angolana}

O objetivo do exercício é analisar se a capacidade de resposta dos depositantes diante da assunção de riscos é afetada pela crise econômica e financeira angolana, avaliando a maior acuidade da monitorização durante o período de dificuldades. As alterações do comportamento dos depositantes antes e durante a crise são apresentadas na Tabela 8. 
TABELA 8

Disciplina do depositante e crise em Angola

\begin{tabular}{|c|c|c|c|c|c|c|}
\hline \multirow{3}{*}{$\begin{array}{l}\text { Variáveis } \\
\text { Risco e } \\
\text { Controle }\end{array}$} & \multicolumn{3}{|c|}{$2008-2013$} & \multicolumn{3}{|c|}{$2014-2017$} \\
\hline & \multicolumn{2}{|c|}{ Vardep $_{i, t}$} & \multirow{2}{*}{$\begin{array}{l}R_{i, t} \\
(\mathbf{3})\end{array}$} & \multicolumn{2}{|c|}{ Vardep $_{i, t}$} & \multirow{2}{*}{$\begin{array}{l}R_{i, t} \\
(6)\end{array}$} \\
\hline & (1) & (2) & & (4) & (5) & \\
\hline$A C_{i, t-1}$ & $\begin{array}{c}0.3858 \\
(0.9117)\end{array}$ & $\begin{array}{c}-0.6983 \\
(-0.8699)\end{array}$ & $\begin{array}{c}0.0224 \\
(0.9838)\end{array}$ & $\begin{array}{c}1.6748^{* * *} \\
(3.8987)\end{array}$ & $\begin{array}{c}2.3354 \\
(0.7505)\end{array}$ & $\begin{array}{c}-0.0126 \\
(-1.4015)\end{array}$ \\
\hline$I M P_{i, t-1}$ & $\begin{array}{c}-2.1000^{* * *} \\
(-6.4836)\end{array}$ & $\begin{array}{c}0.1151 \\
(0.1204)\end{array}$ & $\begin{array}{c}0.1241^{* *} \\
(2.1500)\end{array}$ & $\begin{array}{c}0.4172^{* *} \\
(2.0798)\end{array}$ & $\begin{array}{c}0.5243 \\
(0.9712)\end{array}$ & $\begin{array}{c}-0.0019 \\
(-0.3722)\end{array}$ \\
\hline$E f_{i, t-1}$ & $\begin{array}{c}0.0098^{* * *} \\
(4.5685)\end{array}$ & $\begin{array}{c}0.0136 * * * \\
(4.4425)\end{array}$ & $\begin{array}{r}-8.53 \mathrm{E}-05 \\
(-1.0713)\end{array}$ & $\begin{array}{c}0.0027 \\
(0.8016)\end{array}$ & $\begin{array}{c}0.0006 \\
(0.0647)\end{array}$ & $\begin{array}{c}-9.84 \mathrm{E}-05^{*} \\
(-1.8889)\end{array}$ \\
\hline$R O A_{i, t-1}$ & $\begin{array}{c}-0.0706 \\
(-0.1507)\end{array}$ & $\begin{array}{c}0.2809 \\
(0.4285)\end{array}$ & $\begin{array}{c}-0.0056 \\
(-0.2151)\end{array}$ & $\begin{array}{c}-1.0919^{* * *} \\
(-2.6856)\end{array}$ & $\begin{array}{c}-1.0535^{* *} \\
(-2.3262)\end{array}$ & $\begin{array}{c}0.0095 \\
(1.2039)\end{array}$ \\
\hline$L I Q_{i, t-1}$ & $\begin{array}{c}-0.1449 \\
(-0.6779)\end{array}$ & $\begin{array}{c}-0.1138 \\
(-1.6325)\end{array}$ & $\begin{array}{c}-0.0292^{* *} \\
(-2.1558)\end{array}$ & $\begin{array}{l}0.5643^{* *} \\
(2.0533)\end{array}$ & $\begin{array}{c}0.5013 \\
(1.2334)\end{array}$ & $\begin{array}{c}-0.0211 * * * \\
(-2.7679)\end{array}$ \\
\hline Ativo $_{i, t}$ & $\begin{array}{c}4.91 \mathrm{E}-09 \\
(0.0132)\end{array}$ & $\begin{array}{c}9.82 \mathrm{E}-07^{*} \\
(1.6907)\end{array}$ & $\begin{array}{c}-0.0005 \\
(-0.4270)\end{array}$ & $\begin{array}{l}1.53 \mathrm{E}-07 \\
(0.3631)\end{array}$ & $\begin{array}{l}2.54 \mathrm{E}-07 \\
(0.3973)\end{array}$ & $\begin{array}{c}-0.0024^{* *} \\
(-2.4870)\end{array}$ \\
\hline Agências $_{i, t}$ & $\begin{array}{c}-0.0006 \\
(-0.9725)\end{array}$ & $\begin{array}{c}0.0006 \\
(0.7810)\end{array}$ & $\begin{array}{l}2.46 \mathrm{E}-05 \\
(1.0574)\end{array}$ & $\begin{array}{c}-9.64 \mathrm{E}-05 \\
(-0.1759)\end{array}$ & $\begin{array}{c}-3.79 \mathrm{E}-06 \\
(0.3273)\end{array}$ & $\begin{array}{c}7.39 \mathrm{E}-05^{* * *} \\
(4.1598)\end{array}$ \\
\hline$D T S B_{t}$ & $\begin{array}{l}1.09 \mathrm{E}-08 \\
(0.3544)\end{array}$ & $\begin{array}{c}-4.21 \mathrm{E}-07^{* * *} \\
(-3.0877)\end{array}$ & & $\begin{array}{l}4.08 \mathrm{E}-08 \\
(0.6369)\end{array}$ & $\begin{array}{c}2.85 \mathrm{E}-08 \\
(0.32733)\end{array}$ & \\
\hline$T M D S B_{t}$ & & & $\begin{array}{c}-0.1215 \\
(-1.0317)\end{array}$ & & & $\begin{array}{l}0.5311^{* * *} \\
(2.4715)\end{array}$ \\
\hline$|n f|_{t}$ & $\begin{array}{c}3.8140^{* * * *} \\
(4.8893)\end{array}$ & $\begin{array}{l}-6.1153^{*} \\
(-1.8094)\end{array}$ & $\begin{array}{l}0.3165^{* *} \\
(2.2356)\end{array}$ & $\begin{array}{l}-1.2105 \\
(-1.3664)\end{array}$ & $\begin{array}{l}-1.2046 \\
(-1.3286)\end{array}$ & $\begin{array}{l}0.0468^{* *} \\
(2.4653)\end{array}$ \\
\hline$P I B_{t}$ & $\begin{array}{c}0.3377 \\
(0.3627)\end{array}$ & $\begin{array}{c}-3.7572^{* *} \\
(-2.0979)\end{array}$ & $\begin{array}{c}0.1021 \\
(1.4452)\end{array}$ & $\begin{array}{c}-8.3731 \\
(-1.2929)\end{array}$ & $\begin{array}{c}-9.1167 \\
(-1.2193)\end{array}$ & $\begin{array}{l}0.4367^{* *} \\
(2.5367)\end{array}$ \\
\hline $\begin{array}{l}\text { Número de } \\
\text { bancos }\end{array}$ & 21 & 21 & 20 & 24 & 24 & 23 \\
\hline Observações & 102 & 102 & 100 & 61 & 61 & 64 \\
\hline $\begin{array}{l}\text { Estimador } \\
\text { (tipo) }\end{array}$ & PLS pooled & PTSLS & PLS & PLS & PTSLS & PLS \\
\hline$R_{\text {Ajustado }}^{2}$ & 0.4443 & 0.5109 & 0.1759 & 0.4999 & 0.4768 & 0.4863 \\
\hline $\begin{array}{l}\text { F-Statistic } \\
(\text { valor }-p)\end{array}$ & & $\begin{array}{c}4.5180 \\
(0,0000)\end{array}$ & & & & \\
\hline DW & 2,261 & 2,723 & 1,886 & 1.824 & 1,779 & \\
\hline
\end{tabular}

Fonte: Elaborada pelo autor.

Notas:

- A constante não é reportada no quadro, embora possa constar das regressões.

- As estatísticas $t$ estão entre parênteses.

- Foram obtidos erros padrão robustos utilizando white standard errors \& covariance (d.f. corrected) para a heterocedasticidade.

_***** e $^{*}$ indicam os níveis de significância de $1 \%, 5 \%$ e $10 \%$, respectivamente. 
O período de análise foi dividido em 2 subperíodos: 2008-2013 e 2014-2017. As 3 primeiras estimações se referem aos resultados do período pré-crise, sendo a disciplina dos depositantes pouco evidente nesse intervalo, tanto na equação do crescimento dos depósitos como nos juros pagos. Embora os coeficientes de 2 variáveis de risco sejam estatisticamente significativos (IMP e Ef) para explicar o crescimento dos depósitos, o sinal do indicador de eficiência se mostra contrário à teoria. Em contraste, a adequação de capital, a rentabilidade e a liquidez, não desempenham qualquer papel na escolha dos bancos pelos depositantes. A taxa dos depósitos aparece associada a 2 variáveis de risco com significado estatístico e os sinais previstos: qualidade dos ativos e liquidez. O tamanho é um fator explicativo que afeta o crescimento dos depósitos no período pré-crise, não tendo, no entanto, efeito sobre as taxas de juros pagas. Além disso, os depositantes durante esse período foram sensíveis ao nível da inflação que afetou positivamente a taxa de juros dos depósitos: os bancos responderam ao aumento da inflação aumentando a taxa de depósitos.

A disciplina melhorou um pouco no segundo período, sobretudo para o crescimento dos depósitos, confirmando que as reações do mercado possam ser mais acentuadas na sequência de crises. Agora, as variáveis de risco bancário são um pouco mais explicativas e significativas em comparação ao período pré-crise. Assim, a conjuntura desfavorável parece ter tido um efeito positivo, ainda que limitado, na disciplina de mercado. A adequação do capital $(A C)$ e a liquidez (LIQ) são fatores que condicionam o crescimento dos depósitos enquanto os sinais das variáveis rentabilidade e qualidade dos ativos evidenciam contradição com o previsto. A liquidez é a variável de risco que melhor parece explicar os juros pagos. Em síntese, a crise financeira e os problemas com o não cumprimento das carteiras de crédito, a par com a crise econômica, possivelmente funcionaram, ainda que de modo pouco pronunciado, como alerta para os depositantes.

\section{Conclusão}

Este artigo analisa a hipótese da disciplina dos depositantes no setor bancário angolano, testando empiricamente sua eficácia na fase de monitorização, por meio das abordagens da quantidade e do preço dos depósitos.

Os resultados obtidos e apresentados comprovam que os depositantes em Angola se comportam de modo pouco consistente com a disciplina de mercado e não se alinham às conclusões dos principais estudos de referência para os mercados emergentes (MARTINEZ PERIA e SCHMUKLER, 2001; DEMIRGÜÇ-KUNT e HUIZINGA, 2004; GALINDO, POWELL e LOBOGUERRERO, 2005; LEVY-YEYATI, MARTINEZ PERIA e SCHMUKLER, 2010). Não obstante, estão mais próximos do argumento de Karas, Pyle e Schoors (2009) de que os depositantes disciplinam os bancos principalmente a partir dos montantes dos depósitos.

A premissa fundamental da disciplina dos depositantes é estes sinalizarem o aumento do risco bancário por meio de taxas de juros mais elevadas e menor disponibilidade de fundos. Entretanto, como se mostra evidente no estudo, os fatores de risco incluídos nos modelos acabam por explicar uma pequena parcela da variação dos depósitos e das taxas dos bancos. A disciplina não forneceu avisos oportunos sobre o risco bancário nem impediu sua acumulação, manifestada, por exemplo, nos episódios de dificuldades financeiras em instituições angolanas. Os bancos de melhor qualidade não parecem capazes de atrair mais depósitos, emergindo a taxa 
de adequação do capital como a única variável de risco com significado estatístico e impacto sobre o crescimento dos depósitos. A fraca monitorização promovida pelos depositantes se manteve durante o período de crise, embora com ligeiro fortalecimento, contrariando as situações observadas em outros mercados nos quais os investidores se tornaram bastante sensíveis ao risco. Tais resultados e conclusões constituem uma boa base exploratória para o estudo e a compreensão da disciplina promovida pelos depositantes no mercado bancário angolano e sua importância decorre das implicações para a política regulatória diante da evidência de que os instrumentos da disciplina não são utilizados com a eficácia preconizada pela teoria. Embora este estudo não tenha por objetivo oferecer sugestões de política regulatória, decerto o regulador terá de desenvolver esforços e tomar medidas para remover os obstáculos que impedem os depositantes de monitorizar de modo efetivo o comportamento de risco dos bancos. Abremse portas para discutir várias questões. Primeiro, é necessário reduzir as expetativas dos depositantes quanto a possíveis intervenções do governo e a resgates de bancos insolventes. Segundo, é necessário melhorar a transparência, reforçando a divulgação de informação ao público e adotando plenamente as regras contabilísticas internacionais. Terceiro, é preciso olhar de modo mais atento as questões de governança das instituições, alinhando os interesses dos gestores aos da regulação prudencial. Por fim, constata-se a necessidade de promover estratégias que contribuam para elevar o nível de educação financeira dos depositantes em Angola, melhorando a monitorização por parte deles. 


\section{Referências}

ALANIS, E.; BELADI, H.; QUIJANO, M. Uninsured deposits as a monitoring device: their impact on bond yields of banks. Journal of Banking \& Finance, v. 52, p. 77-88, 2015.

BARAJAS, A.; STEINER R. Depositor behavior and market discipline in Colombia. Washington, D.C.: International Monetary Fund, 2000. (IMF Working Paper N. 00/214).

BERGER, A. Market discipline in banking. In: CONFERENCE ON BANK STRUCTURE AND COMPETITION, 27., 1991, Chicago. Proceedings... Chicago, IL: Federal Reserve Bank of Chicago, 1991. p. 419-437.

BERGER, A. N.; TURK-ARISS, R. Do depositors discipline banks and did government actions during the recent crisis reduce this discipline? An international perspective. Journal of Financial Services Research, v. 48, n. 2, p. 103-126, 2015.

BLISS, R. R.; FLANNERY, M. J. Market discipline in the governance of US bank holding companies: monitoring vs. influencing. Review of Finance, v. 6, n. 3, p. 361-396, 2002.

CALOMIRIS, C. W.; POWELL, A. Can emerging market bank regulators establish credible discipline? The case of Argentina, 1992-99. In: MISHKIN, F. S. (Ed.). Prudential supervision: what works and what doesn't. Chicago, IL: University of Chicago Press, 2001. p. 147-196.

COOK, D. O.; SPELLMAN, L. J. Repudiation risk and restitution costs: toward understanding premiums on insured deposits. Journal of Money, Credit and Banking, v. 26, n. 3, p. 439-459, 1994.

CROCKETT, A. Market discipline and financial stabilities. Journal of Banking and Finance, v. 26, n. 5, p. 977-987, 2002.

DEMIRGÜÇ-KUNT, A.; HUIZINGA, H. Market discipline and deposit insurance. Journal of Monetary Economics, v. 51, n. 2, p. 375-399, 2004.

DICKEY, D. A.; FULLER, W. A. Distribution of the estimators for autoregressive time series with a unit root. Journal of the American statistical association, v. 74, n. 366, 427-431, 1979.

GALINDO, A. J.; POWELL, A. P.; LOBOGUERRERO, A. M. Latin American banks, market discipline and official regulation: completing the circle. 2005. Disponível em: <http://dx.doi.org/10.2139/ ssrn.712883 >. Acesso em: 07 maio 2019.

GHOSH, S.; DAS, A. Market discipline in the Indian banking sector. Mumbai: National Stock Exchange of India, 2003. (NSE Working Paper N. 24).

GILBERT, R. A.; VAUGHAN, M. D. Do depositors care about enforcement actions? Journal of Economics and Business, v. 53, n. 2-3, p. 283-311, 2001.

GREENSPAN, A. Harnessing market discipline. The Region, v. 15, n. 3, p. 6-7, 2001.

HAMALAINEN, P.; HALL, M.; HOWCROFT, B. Market discipline: a theoretical framework for regulatory policy development. In: KAUFMAN, G. (Ed.). Market discipline in banking: theory and evidence. Amsterdam: Elsevier, 2003. p. 57-95. 
HAMALAINEN, P.; HALL, M.; HOWCROFT, B. A framework for market discipline in bank regulatory design. Journal of Business Finance \& Accounting, v. 32, n. 1-2, p. 183-209, 2005.

HASAN, I. et al. Market discipline during crisis: evidence from bank depositors in transition countries. Journal of Banking \& Finance, v. 37, n. 12, p. 5436-5451, 2013.

HOSONO, K.; IWAKI, H.; TSURU, K. Bank regulation and market discipline around the world. Tokyo: The Research Institute of Economy, Trade and Industry, 2004. (RIETI Discussion Paper Series N. 04-E-031).

HOSONO, K.; IWAKI, H.; TSURU, K. Banking crises, deposit insurance, and market discipline: lessons from the Asian crises. Tokyo: The Research Institute of Economy, Trade and Industry, 2005. (RIETI Discussion Paper Series N. 05-E-029).

HOU, X.; GAO, Z.; WANG, Q. Internet finance development and banking market discipline: evidence from China. Journal of Financial Stability, v. 22, p. 88-100, 2016.

JAGTIANI, J.; KAUFMAN, G.; LEMIEUX, C. Do markets discipline banks and bank holding companies? Evidence from debt pricing. Chicago, IL: Federal Reserve Bank of Chicago, 2000. (Emerging Issues Series S\&R-99-3R).

KARAS, A.; PYLE, W.; SCHOORS, K. How do Russian depositors discipline their banks? Evidence of a backward bending deposit supply function. Oxford Economic Papers, v. 62, n. 1, p. 36-61, 2009.

LEVY-YEYATI, E.; MARTINEZ PERIA, M. S.; SCHMUKLER, S. L. Depositor behavior under macroeconomic risk: evidence from bank runs in emerging economies. Journal of Money, Credit and Banking, v. 42, n. 4, p. 585-614, 2010.

LLEWELLYN, David T. Alternative approaches to regulation and corporate governance in financial firms. In: BREARLEY, R. et al. (Eds.). Financial Stability and Central Banks. New York: Routledge, 2002. p. 125-161.

MAECHLER, A.; MCDILL, K. Dynamic depositors discipline in US banks. Journal of Banking and Finance, v. 30, n. 7, p. 1871-1898, 2006.

MARTINEZ PERIA, M. S.; SCHMUKLER, S. L. Do depositors punish banks for bad behavior? Market discipline, deposit insurance, and banking crises. The Journal of Finance, v. 56, n. 3, p. 1029-1051, 2001.

NIER, E; BAUMANN, U. Market discipline, disclosure and moral hazard in banking. Journal of Financial Intermediation, v. 15, n. 3, p. 332-361, 2006.

OLSSON, C. Risk management in emerging markets. London: Financial Times/Prentice Hall, 2002.

ROMERA, M.; TABAK, B. Testing for market discipline in the Brazilian banking industry. Banks and Bank Systems, v. 5, n. 3, p. 112-128, 2010.

SHIMIZU, K. Is the information produced in the stock market useful for depositors? Finance Research Letters, v. 6, n. 1, p. 34-39, 2009.

TSURU, K. Depositors' selection of banks and the deposit insurance system in Japan: empirical evidence and its policy implications. Tokyo: The Research Institute of Economy, Trade and Industry, 2003. (RIETI Discussion Paper Series N. 03-E-024). 
UNGAN, E.; CANER, S.; ÖZYILDIRIM, S. Depositors' assessment of bank riskiness in the Russian Federation. Journal of Financial Services Research, v. 33, n. 2, p. 77-100, 2008.

WU, Y.; BOWE, M. Information disclosure and depositor discipline in the Chinese banking sector. Journal of International Financial Markets, Institutions and Money, v. 22, n. 4, p. 855-878, 2012.

\section{CARLOS MOTA}

ORCID: https://orcid.org/0000-0001-9807-2528

Doutor em Gestão (especialidade em Finanças) pela Universidade Portucalense; Professor adjunto no Instituto Politécnico do Porto, Portugal. E-mail: carlosfmota@gmail.com 